\title{
Onomatope dalam Buku Cerita Anak Dwibahasa Little Abid Seri Pengetahuan Dasar (Analisis Metode dan Prosedur Penerjemahan)
}

\author{
${ }^{1}$ Enis Fitriani, ${ }^{2}$ Trisnian Ifianti \\ IKIP Budi Utomo, Malang, Indonesia \\ Email: ${ }^{1}$ enisfitriani@budiutomomalang.ac.id, \\ 2trisnianifianti@budiutomomalang.ac.id
}

\begin{tabular}{l}
\hline Tersedia Online di \\
\hline http://www.jurnal.unublitar.ac.id/i \\
ndex.php/briliant
\end{tabular}

Sejarah Artikel

Diterima pada 13 November 2020

Disetujui pada 23 Februar1 2021

Dipublikasikan pada 28 Februari 2021

Hal. 66-76

\section{Kata Kunci: \\ Onomatope; abid; penerjemahan; metode; prosedur}

\section{DOI:}

http://dx.doi.org/10.28926/briliant. v3i4.584

\begin{abstract}
Abstrak: Penelitian deskriptif kualitatif ini memiliki tujuan mengetahui metode dan prosedur dalam menerjemahkan onomatope dari Little Abid Seri Pengetahuan Dasar yang terdiri dari delapan judul buku. Metode penerjemahan yang dipakai secara berurutan dari yang lebih banyak dipakai adalah metode semantik (17) dan metode komunikatif (5). Prosedur penerjemahan yang dipakai secara berurutan dari yang lebih banyaknya digunakan adalah prosedur kesepadanan fungsional (17) dan modulasi (5). Disarankan agar penerjemah agar dapat menggunakan metode penerjemahan adaptasi yang membutuhkan kreativitas dalam mengolah katakata dalam bahasa sasaran agar pembaca anakanak dapat mendapatkankan lebih banyak manfaat dari membaca buku cerita anak dwi bahasa.
\end{abstract}

\section{PENDAHULUAN}

Buku cerita anak di Indonesia yang dwi bahasa, khususnya Bahasa Indonesia dan Bahasa Inggris sudah banyak kita jumpai baik di toko buku konvensional, toko daring, maupun pasar daring (marketplace). Salah satu judul seri buku yang peneliti temukan di toko daring adalah Seri Little Abid. Seri yang diterbitkan oleh PT. Tigaraksa Satria Educational Product Division, Tbk dipilih oleh peneliti karena seri ini memiliki nilai-nilai yang dibutuhkan dalam pendidikan karakter sejak dini dan yang terpenting adalah menggunakan dwibahasa, Bahasa Indonesia dan bahasa Inggris.

Keistimewaan buku cerita anak adalah selalu ada permainan kata yang digunakan, termasuk onomatope. Onomatope (Onomatopoeia) adalah kata atau serangkaian kata yang menirukan suara dari sumber yang ditirukan, misalnya, onomatope suara burung. Dalam Bahasa Indonesia, suara burung biasanya ditulis dengan cit-cit atau cicitcuit, sedangkan dalam bahasa Inggris bunyinya chirp chirp atau tweet tweet, dan dalam bahasa Hindi adalah cheh cheh. Sugahara (2010) mengatakan bahwa onomatope adalah ekspresi bahasa khusus karena bentuk fonologisnya lebih terkait langsung dengan maknanya. Dengan demikian, 
hubungan antara suara dan makna sangat berhubungan dengan kebiasaan atau budaya dan sistem fonologis dari suatu bahasa.

Bahasa adalah bagian dari budaya sehingga tidak mungkin kita menerjemahkan teks dari budaya yang berbeda seperti Indonesia dan Inggris (Vermeer dalam Setyaningsih, 2012). Bahasa Indonesia dan bahasa Inggris memiliki sistem dan budaya bahasa yang berbeda. Oleh karena itu, terjemahan permainan kata dan terjemahan onomatope menarik untuk dibahas lebih lanjut.

Penelitian dalam bidang penerjemahan, terutama yang berfokus pada penerjemahan onomatope atau permainan kata dari bahasa Inggris ke Bahasa Indonesia atau sebaliknya, tidak mudah ditemukan ditemukan. Salah satu penelitian penerjemahan tentang onomatope yang dilakukan oleh Tiwiyanti (2016) menyebutkan bahwa kata-kata onomatope dianggap sulit untuk ditangani. Sedangkan, penelitian tentang metode/prosedur penerjemahan salah satunya dilakukan oleh Mardiana (2010) menghasilkan teknik transposisi dan modulasi yang digunakan penerjemah dalam menerjemahkan cerpen menimbulkan pergeseran untuk mencapai kesepadanan arti antara bahasa sumber dan bahasa sasaran, di mana pergeseran itu menggunakan teknik transposisi dan modulasi, yaitu pergeseran struktur, pergeseran unit, pergeseran kategori dan pergeseran sudut pandang aktif di bahasa sumber menjadi pasif di bahasa sasaran. Karena alasan yang sudah disebutkan dan beberapa hasil penelitian itulah penulis tertarik untuk berkontribusi untuk penelitian penerjemahan onomatope dari bahasa Inggris ke Indonesia atau sebaliknya dengan melakukan penelitian yang berfokus pada metode dan prosedur yang diterapkan dalam menerjemahkan permainan kata dan onomatope.

Dengan kata lain penelitian ini sangat perlu dilakukan karena penelitian tentang penggunaan metode dan prosedur penerjemahan onomatope dari Bahasa Indonesia ke dalam bahasa Inggris khususnya dalam buku cerita anak dwibahasa tidak ditemukan oleh tim peneliti dalam mesin pencari google scholar dalam sepuluh tahun terakhir. Penelitian deskriptif kualitatif ini memiliki tujuan untuk mengetahui metode dan prosedur yang dipakai dalam menerjemahkan onomatope dalam seri buku cerita Little Abid tema Pengetahuan Dasar yang terdiri dari delapan (8) judul buku. Delapan judul buku tersebut antara lain: I Learn about Talking to Others, I learn about Time, I learn about Moving Around, I Learn about Sounds, I Learn about Textures, I Learn about Taste and Smell, I Learn about Colours, dan I Learn about Math.

\section{METODE}

Metode dan prosedur penerjemahan yang digunakan dalam penelitian ini adalah dari Newmark dalam Setyaningsih (2013). Perbedaan antara metode dan prosedur penerjemahan adalah metode berkenaan dengan keseluruhan teks sedangkan prosedur pada kalimat dan satuan-satuan Bahasa yang lebih kecil seperti klausa, frasa, dan kata. adalah:

Adapun langkah-langkah analisis data yang dilakukan tim peneliti

1. membeli seri buku Little Abid yang terdiri dari 26 buku cerita dan 1 buku pedoman orang tua yang sekaligus terjemahan dari buku cerita; 
2. membuat salinan dari 8 judul buku Little Abid dan terjemahannya yang bertema pengetahuan dasar untuk draft analisis;

3. membaca secara keseluruhan 8 judul buku Little Abid dan terjemahannya yang bertema pengetahuan dasar;

4. membaca setiap kalimat dalam bahasa Indonesia lalu membaca kalimat terjemahannya pada 8 judul buku Little Abid yang bertema pengetahuan dasar;

5. menandai kalimat-kalimat yang terindikasi mengandung onomatope;

6. menentukan kata-kata onomatope dengan berdiskusi dan membaca sumber-sumber yang berkaitan dengan onomatope;

7. menentukan metode penerjemahan pada setiap buku yang bertema pengetahuan dasar dengan berdiskusi dan membaca sumber-sumber yang berkaitan dengan penerjemahan;

8. dan menentukan prosedur penerjemahan pada setiap kalimat yang mengandung onomatope dengan berdiskusi dan membaca sumber-sumber yang berkaitan dengan penerjemahan.

\section{HASIL}

Buku cerita fiksi dwibahasa untuk anak-anak yang beredar di Indonesia secara umum dikemas sangat menarik untuk pembacanya. Berdasarkan buku Introduction to Translation Studies karya Reiss dalam Setyaningsih (2013) karya fiksi merupakan teks ekspresif di mana sang penulis mengaplikasikan estetika dalam bahasa yang digunakan untuk menyampaikan pesan. Reiss kemudian mengelaborasikannya agar dapat menerjemahkan teks ekspresif yang mana ciri pentingnya adalah penggunaan bahasa yang menarik dan gaya penulisan tertentu, sehingga metode yang disarankan adalah identifikasi di mana penerjemah harus mengadopsi sudut pandang penulis asli.

Di bagian metode penelitian telah disebutkan bahwa peneliti menggunakan teori dan prosedur terjemahan yang dikemukakan oleh Newmark. Selain itu, peneliti juga menggunakan klasifikasi onomatope yang digunakan oleh Waugh dalam Setyaningsih (2013).

\section{Suara Binatang}

Onomatope dan permainan kata suara binatang yang peneliti temukan terdapat dalam buku yang berjudul I Learn about Sounds sebanyak 2 suara dan I Learn about Math sebanyak 1 suara sepeti yang tersaji dalam Tabel 1.

Tabel 1. Suara Binatang dan Terjemahannya

\begin{tabular}{|r|l|l|l|}
\hline \multicolumn{1}{|c|}{ No. } & \multicolumn{1}{|c|}{ Teks Sumber } & \multicolumn{1}{c|}{ Teks Sasaran } & \multicolumn{1}{c|}{ Judul Buku } \\
\hline 1. & $\begin{array}{l}\text { Sayup-sayup, terdngar burung } \\
\text { pelatuk mematuk pohon, tuk tuk } \\
\text { tuk. (hal. 93) }\end{array}$ & $\begin{array}{l}\text { Faintly they hear the sound } \\
\text { of the woodpecker tapping } \\
\text { on a tree, tock tock tock. } \\
\text { (hal. } 8)\end{array}$ & $\begin{array}{l}\text { Little Abid: I Learn } \\
\text { about Sounds }\end{array}$ \\
\hline 2. & $\begin{array}{l}\text { Seperti alunan musik saat suara } \\
\text { kodok mengorek menimpali, } \\
\text { kwek kwek plung. (hal. 94) }\end{array}$ & $\begin{array}{l}\text { It's like the rhythm two toads } \\
\text { make, crock crock splash. } \\
\text { (hal. 12) }\end{array}$ & $\begin{array}{l}\text { Little Abid: I Learn } \\
\text { about Sounds }\end{array}$ \\
\hline 3. & $\begin{array}{l}\text { Tiba-tiba terdengar suara, } \\
\text { "Meong," kucing kecil } \\
\text { menghampiri Mimi. (hal. 109) }\end{array}$ & $\begin{array}{l}\text { Suddenly, they hear a sound, } \\
\text { "Meong," a small kitten } \\
\text { approaches Mimi. (hal. 12) }\end{array}$ & $\begin{array}{l}\text { Little Abid: I Learn } \\
\text { about Math }\end{array}$ \\
\hline
\end{tabular}




\section{Suara Tabrakan, Semburan, atau Tembakan}

Untuk suara jenis ini peneliti menemukan cukup banyak suara, yaitu pada buku yang berjudul I Learn about Moving Around sebanyak 1 suara dan I Learn about Sounds 3 suara. Secara detail peneliti sajikan dalam Tabel 2.

Tabel 2. Suara Tabrakan, Semburan, atau Tembakan

\begin{tabular}{|c|l|l|l|}
\hline No. & \multicolumn{1}{|c|}{ Teks Sumber } & \multicolumn{1}{|c|}{ Teks Sasaran } & \multicolumn{1}{c|}{ Judul Buku } \\
\hline 1. & $\begin{array}{l}\text { Byuuurr, Sapi } \\
\text { menyemprotkan air dari } \\
\text { mulutnya. (hal. 89) }\end{array}$ & $\begin{array}{l}\text { Splash, Cow squirts water out } \\
\text { of her mouth. (hal. 10-12) }\end{array}$ & $\begin{array}{l}\text { Little Abid: I Learn } \\
\text { about Moving around }\end{array}$ \\
\hline 2. & $\begin{array}{l}\text { Drap, drap, drap, ... sehingga } \\
\text { langkah mereka terdengar } \\
\text { berderap seperti tentara. (hal. } \\
\text { 92-93) }\end{array}$ & $\begin{array}{l}\text { Clop, clop, clop, ... so their } \\
\text { footsteps sound like marching } \\
\text { soldiers. (hal. 4) }\end{array}$ & $\begin{array}{l}\text { Little Abid: I Learn } \\
\text { about Sounds }\end{array}$ \\
\hline 3. & $\begin{array}{l}\text { Rantang pun ditabuh Mimi, } \\
\text { teng teng teng. (hal. 94) }\end{array}$ & $\begin{array}{l}\text { Mimi even starts banging on a } \\
\text { pot, ting ting ting. (hal. 14) }\end{array}$ & $\begin{array}{l}\text { Little Abid: I Learn } \\
\text { about Sounds }\end{array}$ \\
\hline 4. & $\begin{array}{l}\text { Sebagian bertepuk tangan, } \\
\text { prok prok prok. (hal. 94) }\end{array}$ & $\begin{array}{l}\text { The others use their hands, } \\
\text { clap clap clap. (15) }\end{array}$ & $\begin{array}{l}\text { Little Abid: I Learn } \\
\text { about Sounds }\end{array}$ \\
\hline
\end{tabular}

\section{Suara Fenomena Alam}

Suara fenomena alam yang ditemukan peneliti ada pada buku yang berjudul I Learn about Sounds yaitu 3 suara. Secara lengkap, onomatope dan permainan kata yang ditemukan pada jenis suara ini tersaji dalam Tabel 3.

Tabel 3. Suara Fenomena Alam

\begin{tabular}{|c|l|l|l|}
\hline No. & \multicolumn{1}{|c|}{ Teks Sumber } & \multicolumn{1}{|c|}{ Teks Sasaran } & \multicolumn{1}{c|}{ Judul Buku } \\
\hline 1. & $\begin{array}{l}\text { Airnya jernih, bergemericik } \\
\text { melewati bebatuan. (hal. 93) }\end{array}$ & $\begin{array}{l}\text { The water is very clear, the } \\
\text { water frickles around the rocks } \\
\text { and streams. (hal. } 8 \text { ) }\end{array}$ & $\begin{array}{l}\text { Little Abid: I Learn } \\
\text { about Sounds }\end{array}$ \\
\hline 2. & $\begin{array}{l}\text { Ada suara bergemuruh. (hal. } \\
\text { 93) }\end{array}$ & $\begin{array}{l}\text { They hear a deep roar. (hal. } \\
\text { 11) }\end{array}$ & $\begin{array}{l}\text { Little Abid: I Learn } \\
\text { about Sounds }\end{array}$ \\
\hline 3. & $\begin{array}{l}\text {... ketika suara petir } \\
\text { menggelegar, duar! (hal. 95) }\end{array}$ & $\begin{array}{l}\text { when the thunder sounds, } \\
\text { ba-boom! (hal. 19) }\end{array}$ & $\begin{array}{l}\text { Little Abid: I Learn } \\
\text { about Sounds }\end{array}$ \\
\hline
\end{tabular}

\section{Suara Aktivitas Manusia}

Sedangkan suara aktivitas manusia ada banyak yang ditemukan peneliti. Pada buku yang berjudul I Learn about Talking to Others ada 3 suara, I Learn about Time ada 1 suara, I Learn about Sounds ada 1 suara, I Learn about Texture ada 1 suara, I Learn about Taste and Smell ada 2 suara, dan pada buku I Learn about Colors ada 2 suara. Onomatope dan permainan kata tersebut tersaji dalam Tabel 4.

Tabel 4. Suara Aktivitas Manusia

\begin{tabular}{|c|l|l|l|}
\hline No. & \multicolumn{1}{|c|}{ Teks Sumber } & \multicolumn{1}{|c|}{ Teks Sasaran } & \multicolumn{1}{c|}{ Judul Buku } \\
\hline 1. & $\begin{array}{l}\text { "Hmm, Abid belum pernah } \\
\text { bertemu Bibi Sarah, ya, } \\
\text { Kek." (hal. 81) }\end{array}$ & $\begin{array}{l}\text { "Hmm, I've never met Aunt } \\
\text { Sarah, Grandpa." (hal. } 8)\end{array}$ & $\begin{array}{l}\text { Little Abid: I Learn } \\
\text { about Talking to Others }\end{array}$ \\
\hline 2. & $\begin{array}{l}\text { "Horeee, nanti Abid mau } \\
\text { minta oleh-oleh ke Bibi } \\
\text { Sarah." (hal. 82) }\end{array}$ & $\begin{array}{l}\text { "Hurray, I think I'll ask } \\
\text { Aunt Sarah to bring me } \\
\text { something from England. } \\
\text { (hal. } \text { 13) }\end{array}$ & $\begin{array}{l}\text { Little Abid: I Learn } \\
\text { about Talking to Others }\end{array}$ \\
\hline 3. & "Hmm, sebelum tau Inggris & "Hmm, before I tell you & Little Abid: I Learn \\
\hline \hline
\end{tabular}

$$
\begin{array}{r|r}
\text { BRILIANT: Jurnal Riset dan Konseptual } & 69 \\
\text { Volume } 6 \text { Nomor 1, Februari } 2021 &
\end{array}
$$




\begin{tabular}{|c|c|c|c|}
\hline & ..." (hal. 82) & $\begin{array}{l}\text { where England is ...." (hal. } \\
\text { 13) }\end{array}$ & about Talking to Others \\
\hline 4. & $\begin{array}{l}\text { "Hmm, oke, sayang, tapi } \\
\text { nanti pulangnya Abid jalan } \\
\text { sendiri, ya?" (hal. 87) }\end{array}$ & $\begin{array}{l}\text { "Hmm, okay, but you'll } \\
\text { have to walk home." (hal. } \\
\text { 16) }\end{array}$ & $\begin{array}{l}\text { Little Abid: I Learn } \\
\text { about Time }\end{array}$ \\
\hline 5. & $\begin{array}{l}\text { Wow, ini pertama kalinya } \\
\text { Abid belajar menyelam. (hal. } \\
\text { 96) }\end{array}$ & $\begin{array}{l}\text { Wow, Abid has never tried } \\
\text { scuba diving before. (hal. } \\
\text { 02) }\end{array}$ & $\begin{array}{l}\text { Little Abid: I Learn } \\
\text { about Texture }\end{array}$ \\
\hline 6. & $\begin{array}{l}\text { "Huaaaah, ikannya terlalu } \\
\text { pedas!" (hal. 101) }\end{array}$ & $\begin{array}{l}\text { "Whoa, the fish is too } \\
\text { spicy!" (hal. 18) }\end{array}$ & $\begin{array}{l}\text { Little Abid: I Learn } \\
\text { about Taste and Smell }\end{array}$ \\
\hline 7. & $\begin{array}{l}\text { "Waaaw, wangi sekali } \\
\text { bunganya," kata Bunda. (hal. } \\
\text { 103) }\end{array}$ & $\begin{array}{l}\text { "Wow, it smells wonderful," } \\
\text { says Mother. (hal. 15) }\end{array}$ & $\begin{array}{l}\text { Little Abid: I Learn } \\
\text { about Taste and Smell }\end{array}$ \\
\hline 8. & $\begin{array}{l}\text { "Horeee!" kata Abid sambal } \\
\text { bersorak. (hal. 104) }\end{array}$ & $\begin{array}{l}\text { "Hurray!" cheers Abid. } \\
\text { (hal. 03) }\end{array}$ & $\begin{array}{l}\text { Little Abid: I Learn } \\
\text { about Colors }\end{array}$ \\
\hline 9. & $\begin{array}{l}\text { "Wow, bagus!" kata Abid. } \\
\text { (hal. 105) }\end{array}$ & $\begin{array}{l}\text { "Wow, that's nice!" says } \\
\text { Abid. (hal. 08) }\end{array}$ & $\begin{array}{l}\text { Little Abid: I Learn } \\
\text { about Colors }\end{array}$ \\
\hline
\end{tabular}

\section{Suara yang Dihasilkan Mesin}

Suara yang dihasilkan mesin yang ditemukan peneliti hanya ada pada buku yang berjudul I Learn about Sound yaitu sebanyak 3 suara. Onomatope dan permainan kata yang ditemukan pada jenis suara ini tersaji dalam Tabel 5.

Tabel 5. Suara yang Dihasilkan Mesin

\begin{tabular}{|r|l|l|l|}
\hline No. & \multicolumn{1}{|c|}{ Teks Sumber } & \multicolumn{1}{|c|}{ Teks Sasaran } & \multicolumn{1}{c|}{ Judul Buku } \\
\hline 1. & $\begin{array}{l}\text { Priiit, priiit, belum jauh } \\
\text { melangkah terdengar bunyi } \\
\text { peluit. (hal. 93) }\end{array}$ & $\begin{array}{l}\text { Preet, preet, after a short } \\
\text { time, they hear the sound of } \\
\text { the whistle. } \text { (hal. 07) }\end{array}$ & $\begin{array}{l}\text { Little Abid: I Learn } \\
\text { about Sound }\end{array}$ \\
\hline 2. & $\begin{array}{l}\text { Dentingan gitar terdengar } \\
\text { sangat merdu, jreng, jreng. } \\
\text { (hal. 94) }\end{array}$ & $\begin{array}{l}\text { The strumming of the guitar } \\
\text { is quite melodic. (hal. 14) }\end{array}$ & $\begin{array}{l}\text { Little Abid: I Learn } \\
\text { about Sound }\end{array}$ \\
\hline 3. & $\begin{array}{l}\text { Terdengar suara klakson } \\
\text { mobil dari luar, tiiin, tiiin. } \\
\text { (hal. 95) }\end{array}$ & $\begin{array}{l}\text { The sound of the horn can be } \\
\text { heard, honk, honk. (hal. 17) }\end{array}$ & $\begin{array}{l}\text { Little Abid: I Learn } \\
\text { about Sound }\end{array}$ \\
\hline
\end{tabular}

Dengan demikian, onomatope suara binatang yang peneliti temukan ada di buku yang berjudul I Learn about Sounds sebanyak 2 suara dan I Learn about Math sebanyak 1 suara; untuk suara tabrakan, semburan, atau tembakan terdapat pada buku yang berjudul I Learn about Moving Around sebanyak 1 suara dan I Learn about Sounds 3 suara; suara fenomena alam ada pada buku yang berjudul $I$ Learn about Sounds yaitu 3 suara; suara aktivitas manusia terdapat pada buku yang berjudul I Learn about Talking to Others ada 3 suara, I Learn about Time ada 1 suara, I Learn about Sounds ada 1 suara, I Learn about Texture ada 1 suara, I Learn about Taste and Smell ada 2 suara, dan pada buku I Learn about Colors ada 2 suara; dan suara yang dihasilkan mesin ada pada buku yang berjudul I Learn about Sound yaitu sebanyak 3 suara.

\section{PEMBAHASAN}

Teori penerjemahan Newmark dalam Setyaningsih (2013) menyebutkan ada delapan metode penerjemahan, yaitu: penerjemahan kata-demi-kata, 
penerjemahan literal, penerjemahan setia, penerjemahan semantik, adaptasi, penerjemahan bebas, penerjemahan idiomatik, dan penerjemahan komunikatif. Jika dibagi berdasarkan kecenderungan mengakomodasi bahasa sumber atau bahasa sasaran, empat metode pertama lebih mengakomodasi bahasa sumber sedangkan sisanya lebih mengakomodasi bahasa sasaran.

Dalam pandangannya, Newmark, dalam Machali (2009), terdapat empat belas prosedur dalam penerjemahan. Namun Machali mengatakan bahwa tidak semua prosedur yang disebutkan oleh Newmartk tersebut dapat digunakan oleh penerjemah khususnya penerjemah dengan bahasa pasangan bahasa Indonesia dan bahasa Inggris, sehingga, lima dari empat belas prosedur Newmark yang dianggap relevan antara lain: transposisi, modulasi, adaptasi, dan pemadanan berkonteks dan pemadanan bercatatan.

Dalam pemahasan secara lengkap, peneliti membaginya berdasarkan klasifikasi onomatope yang digunakan oleh Waugh dalam Setyaningsih (2013) dalam buku cerita dwibahasa Little Abid Seri Pengetahuan Dasar, yaitu: suara binatang, suara tabrakan/ semburan/ tembakan, suara fenomena alam, suara aktifitas manusia, dan suara yang dihasilkan mesin.

\section{Suara Binatang}

Dalam buku I Learn about Sounds, diceritakan ada burung pelatuk yang sedang mematuk dan diilistrasikan dengan "tuk tuk tuk" dan diterjemahkan ke dalam Bahasa Inggris menjadi "tock, tock, tock" namun dalam buku Onomatopoeia Sounds Like suara burung pelatuk adalah "peck" atau "click". Sedangkan suara kodok mengorek yang digambarkan dengan "kwek, kwek, plung" dalam Bahasa Indonesia diterjemahkan menjadi "crock crock splash namun dengan penulisan "croak" dalam Onomatopoeia Sounds Like (2020), www.onomatopeialist.com (2013) dan www.fluentu.com (2020).

Dalam buku I Learn about Math peneliti menemukan suara kucing "meong" dalam Bahasa Indonesia, kata itu diterjmahkan ke dalam Bahasa Inggris menjadi "meow" yang mana kata ini terdapat dalam buku Onomatopoeia Sounds Like (2020), www.onomatopeialist.com (2013) dan www.fluentu.com (2020).

Berdasarkan hasil penerjemahan suara binatang tersebut dapat diketahui bahwa metode penerjemahan yang digunakan adalah metode penerjemahan semantik karena hasil terjemahan mempertimbangkan unsur estetika bahasa sumber dan memilih makna yang dapat dimengerti dengan mudah dan tidak ada pemadanan budaya.

Sedangkan prosedur penerjemahannya adalah kesepadanan fungsional karena hasil penerjemahan sesuai dengan apa yang dibutuhkan oleh pembaca yang masih anak-anak, yaitu kata-kata yang sederhana dan mudah dimengerti.

\section{Suara Tabrakan, Semburan, atau Tembakan}

Dalam buku I Learn about Moving Around kata "byuuuuur" diterjemahkan menjadi "splash" terdapat dalam www.mirriam-webster.com (2020), www.onomatopeialist.com (2013), dan www.writtensound.com (2020). Dalam buku I Learn about Sounds suara langkah berderap "drap, drap, drap" diterjemahkan menjadi "clop, clop, clop" terdapat dalam 
www.onomatopeialist.com (2013) dan www.writtensound.com (2020). Suara tabuhan rantang "teng, teng, teng" menjadi "ting, ting, ting" terdapat dalam Rulihapsari (2010) dan www.onomatopeialist.com (2013), dan suara tepuk tangan "prok, prok, prok" menjadi "clap, clap, clap" terdapat dalam Chang (2018), Rulihapsari (2010), dan www.onomatopeialist.com (2013).

Dari hasil penerjemahan suara tabrakan, semburan, atau tembakan yang telah ditemukan dapat diketahui bahwa metode penerjemahan yang digunakan juga metode penerjemahan semantic karena hasil terjemahan mempertimbangkan unsur estetika bahasa sumber dan memilih makna yang bisa dimengerti dengan mudah mengingat pembaca yang masih anak-anak diharapkan dapat mengetahui arti dari suara tabrakan, semburan, atau tembakan yang dimaksud dalam bahasa sasaran dengan mudah dengan digunakannya metode ini.

Prosedur penerjemahannya juga kesepadanan fungsional karena hasil sesuai untuk anak-anak yang hanya membutuhkan kata-kata yang sederhana dan mudah dipahami.

\section{Suara Fenomena Alam}

Suara fenomena alam yang ditemukan peneliti ada pada buku yang berjudul I Learn about Sounds yaitu 3 suara.

Buku I Learn about Sounds tertulis “... (air) bergemericik melewati bebatuan" diterjemahkan menjadi "the water freckles around the rocks and streams". Sedangkan kalimat "Ada suara bergemuruh" diterjemahkan menjadi "They hear a deep roar". Kedua kalimat yang mengandung onomatope ini diterjemahkan dari frasa ke frasa. Ada juga suara petir "duar" diterjemahkan menjadi "kaboom" seperti dalam Reynolds (2013), Karina (2017), dan www.writeswrite.com (2020).

Berdasarkan hasil penerjemahan suara fenomena alam pada "the water freckles around the rocks and streams" dan "They hear a deep roar" dapat diketahui bahwa metode penerjemahan yang digunakan adalah metode penerjemahan komunikatif karena hasil terjemahan langsung dapat memberikan makna yang lebih jelas dari bahasa sumbernya. Sedangkan prosedur penerjemahannya adalah modulasi bebas karena hasil penerjemahan menambahkan kosa kata untuk memperjelas makna (aspek nonlinguistik).

Untuk hasil penerjemahan suara fenomena alam pada "kaboom" dapat diketahui bahwa metodenya adalah metode penerjemahan semantik karena hasil terjemahan dapat dimengerti dengan mudah dan tidak ada pemadanan budaya. Sedangkan prosedur penerjemahannya adalah modulasi kesetaraan fungsional karena hasil penerjemahan sesuai dengan apa yang dibutuhkan oleh pembaca yang masih anak-anak, yaitu kata-kata yang sederhana dan mudah dimengerti.

\section{Suara Aktivitas Manusia}

Dalam buku yang berjudul I Learn about Moving Around suara "hmm" dalam Bahasa Indonesia saat Abid sedang berpikir tetap diterjemahkan " $h m m$ " dalam Bahasa Inggris seperti pada Pertiwi (2015), Reynolds (2013), dan www.onomatopeialist.com (2013). Ekspresi "horeee" saat Abid merasa senang diterjemahkan menjadi "huray" seperti yang terdapat dalam Sugahara (2011) dan www.onomatopeialist.com (2013). Suara "huaaah" diterjemahkan menjadi 
"whoa" saat Abid merasakan makanan yang panas. Menurut www.onomatoelist.com (2013) dan www.writtensound.com (2020) "whoa" merupakan kata yang digunakan untuk memerintah berhenti (biasanya pada kuda). Ekspresi "wow" dan "waaaw" saat Abid merasa heran dan kagum diterjemahkan menjadi "wow" seperti dalam buku Onomatopoeia Sounds Like (2020), www.ereadingworksheets.com (2019), www.onomatopeialist.com (2013) dan www.writtensound.com (2020).

Dari hasil penerjemahan suara aktivitas manusia yang sudah disebutkan dapat diketahui bahwa metode penerjemahan yang digunakan adalah metode penerjemahan semantik karena hasil terjemahan memperhatikan unsur linguistik bahasa sumber dan memilih makna yang mudah dimengerti juga tidak ada unsur budaya yang mempengaruhi.

Untuk prosedur penerjemahan yang dipilih oleh penerjemah adalah kesepadanan fungsional karena hasil penerjemahan berterima jika ditujukan untuk pembaca anak-anak yang memerlukan kata-kata sederhana dan dapat dipahami dengan mudah.

\section{Suara yang Dihasilkan Mesin}

Buku yang berjudul I Learn about Sounds menggunakan "priiit, priiit" untuk menunjukkan suara peluit diterjemahkan menjadi "preet, preet" sesuai dengan daftar kata onomaptope pada www.onomatopeialist.com (2013), dan www.writtensound.com (2020). Dalam buku I Learn about Sounds juga tertulis "dentingan gitar terdengar sangat merdu, jreng, jreng" diterjemahkan menjadi "the strumming of the guitar is quite melodic". Suara klakson mobil "tiiin, tiiin" diterjemahkan menjadi "honk, honk" sesuai dengan daftar onomatope dalam www.onomatopeialist.com (2013), www.woodwardenglish.com (2011).

Berdasarkan hasil penerjemahan suara yang dihasilkan mesin pada kalimat "the strumming of the guitar is quite melodic" dapat diketahui bahwa metode penerjemahan yang digunakan adalah metode penerjemahan komunikatif karena hasil terjemahan berupa parafrase dan langsung dapat memberikan makna yang lebih detail dari bahasa sumber. Sedangkan prosedur penerjemahannya adalah modulasi bebas karena penerjemah memberikan kosa kata baru untuk memperjelas makna yang berbeda dari kosa kata dalam bahasa sumber (aspek nonlinguistik).

Untuk hasil penerjemahan suara fenomena alam pada "preet, preet" dan "honk, honk" dapat diketahui bahwa metode penerjemahannya adalah metode penerjemahan semantis. Hal ini terlihat dari hasil terjemahan yang mudah dimengerti dan tidak mengandung unsur budaya. Sedangkan prosedur penerjemahan yang digunakan adalah kesepadanan fungsional karena hasil penerjemahan berterima jika ditujukan kepada anak-anak.

Metode penerjemahan yang dipakai oleh penerjemah dalam Little Abid Seri Pengetahuan Dasar secara berurutan dari yang lebih banyaknya dipakai adalah metode semantik (digunakan pada 17 onomatope yang ditemukan) dan metode komunikatif (digunakan pada 5 onomatope yang ditemukan).

Penerjemahan semantis merupakan metode penerjemahan yang berusaha menjaga struktur semantis dan sintaksis serta makna secara konstektual bahasa 
sumber (Pro Translasi, 2017). Dalam metode ini elemen budaya dari bahasa sumber harus tetap dipertahankan meskipun telah diterjemahkan ke dalam bahasa lain. Sedangkan penerjemahan komunikatif adalah metode yang mengusahakan adanya efek yang diperoleh pembaca Bahasa sasaran sedekat mungkin denagn efek yang diperoleh oleh pembaaca bahasa sumber (Newmark dalam Hariyanto, 2013). Dengan menggunakan metode ini hasil terjemahan dapat langsung berterima karena memperhatikan prinsip-prinsip komuniasi.

Prosedur penerjemahan yang dipakai oleh penerjemah dalam Little Abid Seri Pengetahuan Dasar secara berurutan dari yang lebih banyaknya digunakan adalah prosedur kesepadanan fungsional (digunakan pada 17 onomatope yang ditemukan) dan modulasi (digunakan pada 5 onomatope yang ditemukan).

Prosedur kesepadanan fungsional merupakan prosedur umum yang digunakan pada istilah-istilah budaya namun menghendaki penggunaan kata-kata yang bebas dari unsur budaya, bahkan bias menciptakan istilah spesifik yang baru karena prosedur ini menetralkan kata-kata dari bahasa sumber serta memberi tambahan keterangan (Newmark dalam Setyaningsih, 2013). Sedangkan prosedur modulasi adalah startegi yang dilakukan penerjemah untuk mengalihbahasakan frasa, klausa, atau kalimat jika makna literal tidak dapat menghasilkan hasil terjemahan yang tidak berterima (Newmark dalam Astuti (2013). Makna literal tersebut terpengaruh oleh perubahan perspektif, sudut pandang ataupun segi maknawi dari bahasa sumber ke bahasa sasaran.

Seorang penerjemah seharusnya berani untuk bereksperimen dengan kata-kata dan tetap harus memperhatikan susunan tata bahasa dari bahasa sasaran untuk mendapatkan hasil terjemahan yang setara/berterima karena hasil terjemahan harus memiliki makna dan gaya penulisan yang sama dengan teks aslinya.

\section{KESIMPULAN}

Dari hasil temuan dan pembahasan, penerjemah buku Little Abid Seri Pengetahuan Dasar lebih lebih banyaknya dipakai adalah metode semantik (digunakan pada 17 onomatope yang ditemukan) dan metode komunikatif (digunakan pada 5 onomatope yang ditemukan) sedangkan prosedur penerjemahan yang dipakai oleh penerjemah dalam Little Abid Seri Pengetahuan Dasar secara berurutan dari yang lebih banyaknya digunakan adalah prosedur kesepadanan fungsional (digunakan pada 17 onomatope yang ditemukan) dan modulasi (digunakan pada 5 onomatope yang ditemukan) karena penerjemah ingin menekankan pada pemahaman pembaca yang masih anak-anak dengan menggunakan kata-kata yang sederhana dan mudah dimengerti khususnya dalam menambah pengetahuan dasar seperti pengetahuan dasar tentang warna, tekstur, suara, matematika, gerak, berbicara dengan orang lain, waktu, serta rasa dan bau.

\section{SARAN}

Peneliti menyarankan kepada para penerjemah khususnya buku anakanak dapat menggunakan metode penerjemahan adaptasi yang membutuhkan kreativitas dalam mengolah kata-kata dalam bahasa sasaran agar pembaca yang masih anak-anak khususnya yang membutuhkan pengetahuan dasar tentang 
warna, tekstur, suara, matematika, gerak, berbicara dengan orang lain, waktu, serta rasa dan bau dapat mendapatkan manfaat yang lebih ketika membaca buku cerita anak dwi bahasa seri pengetahuan dasar.

\section{DAFTAR RUJUKAN}

Atkins, Marice dkk (Kontributor). Onomatopoeia Sounds Like. https://www.marcieatkins.com/wpcontent/uploads/2013/08/Onomatopoeia-Book-1.pdf

Chang, Aprilia. 2018. The Analysis of Onomatopoeia in The Adventure of Tintin and The Blue Lotus. Pontianak: Universitas Tanjungpura

Gunawan, Adi W. 2015. Mengapa Anak Sulit Konsentrasi? https://www.adiwgunawan.com/articles/mengapa-anak-sulit-konsentrasi

Hariyanto, Sugeng. 2013. Seri Teori (5): Newmark-Jenis Teks, Metode, dan Prosedur https://transkomunika.com/en_US/blog/newmark/

Penerjemahan.

Haywood. 2009. Thinking Spanish Translation. New York: Routledge

Hidayat, Amrullah. 2016. The Onomatopoeia in Robert Vendetti's Comic The Flash. Universitas Islam Negeri Alauddin State Makassar. Makassar: Skripsi. http://repositori.uinalauddin.ac.id/6170/1/AMRULLAH\%20NUR\%20HIDAYAT.pdf diakses pada 9 Maret 2019

https://en.wikipedia.org/wiki/Cross-linguistic_onomatopoeias diakses pada 15 Agustus 2019

http://www.ereadingworksheets.com diakses pada 15 Agustus 2019

https://id.wikipedia.org/wiki/Onomatope diakses pada 9 Agustus 2019

https://www.ereadingworksheets.com/figurative-language/poeticdevices/onomatopoeia-examples/ diakses pada 15 Agustus 2019

http://onomatopoeialist.com/ diakses pada 9 Agustus 2019

http://www.woodwardenglish.com diakses pada 15 Agustus 2019

http://www.writeswrite.com diakses pada 15 Agustus 2019

http://www.writtensound.com/ diakses pada diakses pada 15 Agustus 2019

Karina, Marietta Dea. 2017. English Onomatopoeia in Children's Books: Types and Readers' Understanding. Sanata Dharma University Yogyakarta. Yogyakarta: unpublished thesis. https://repository.usd.ac.id/13176/2/134214060_full.pdf

Karina, Marietta Dea. 2017. English Onomatopoeia in Children's Book: Types and Readers' Understanding. Yogyakarta: Universitas Sanata Dharma

Lestari, Flori. 2014. Onomatopoeia Translation in Wreck-It Ralph the Movie. State Islamic University Syarif Hidayatullah. Jakarta http://repository.uinjkt.ac.id/dspace/bitstream/123456789/31857/1/FLOR I\%20LESTARI-FAH diakses pada 9 Maret 2019

Machali, Rochayah. 2009. Pedoman bagi Penerjemah. Bandung: Kaifa, PT Mizan Pustaka

Mardiana, Wiwik. 2010. Teknik Transposisi dan Modulasi: Kesepadanan dan Pergeseran dalam Penerjemahan Cerpen Berjudul My Beloved Edith. file:///D:/daily\%20files\%209april2019/IKIP\%20Budi\%20Utomo/PENEL 
ITIAN/PDP\%20TA\%202020\%20onomatopoeia\%20research/788920280-1-PB.pdf

Nugraha, Rizki Siddiq.2017. Karakteristik Buku Cerita untuk Anak. http://www.tintapendidikanindonesia.com/2017/04/karakteristik-bukucerita-untuk-anak.html diakses pada 15 Agustus 2019

Pertiwi, Dewi Hana. 2015. Translation of Onomatopoeia and Iconicity in Children Story Book: Crocoffein-Coffee of Friendship by Watiek Idoe and Fitri Kurniawan. Jakarta: Uniersitas Islam Negeri Syarif Hidayatullah

Rahmawati, Dewi Arifiani. 2014. Perbandingan Tingkat Konsentrasi Belajar Anak Sekolah Dasar Dilihat dari Kebiasaan Makan Pagi. Jurnal Early Childhood Education Papers (BELIA) vol. 3 no. 1 tahun2014 https://journal.unnes.ac.id/sju/index.php/belia/article/view/3418/3086

Reynolds, Alison. 2013. A List of Onomatopoeia Words. http://www.alisonreynolds.com.au/?p=1407

Setyaningsih, Retno W. 2013. Onomatopoeia in Bilingual Children Story Books: Methods and Procedures of Translation dalam Setyaningsih, Retno W. dan Machali, Rochayah. Topik-Topik dalam Kajian Penerjemahan. Surabaya: Airlangga University Press

Siregar, Siti Aman. 2012. An Analysis on the Onomatopoeia Words in Donald Duck Comic. Jambi: Batanghari University. https://plus.google.com/111201032851764476923/posts/2kucWsMRb4i

Sugahara, Takashi. 2010. Onomatopoeia in Spoken and Written English: Corpus and Usage Based Analysis. Hokkaido: Hokkaido University

Sumaryanti, Lilis. 2017. Peran Lingkungan terhadap Perkembangan Anak. Jurnal MUADDIB vol. 07 no. $01 \quad$ Januari-Juli 2017. http://download.portalgaruda.org/article.php?article=59263\&val=4093

Tiwiyanti, Leni. 2016. An Analysis on Onomatopoeic Words and Their Translation Procedures in Harry Potter and the Prisoner of Azkaban and Its Translation Version. Scope: Journal of English Language Teaching vol. 01 no. $01 \quad$ September 2016. https://journal.lppmunindra.ac.id/index.php/SCOPE/article/view/870

Translasi, Pro. 2017. Terjemahan Semantis dan Komunikatif. https://www.terjemahinggrisindonesia.com/terjemahan-semantis-dankomunikatif.html\#: :text=Terjemahan\%20komunikatif\%20berusaha\%20 menciptakan\%20efek,dialami\%20oleh\%20pembaca\%20bahasa\%20sumb er.\&text=Sedangkan\%20terjemahan $\% 20$ semantic\%20berusaha\%20mem pertahankan,kontekstual\%20dari\%20teks\%20bahasa\%20sumber 